\title{
Advances in the Assessment of Fibromyalgia
}

\author{
David A. Williams, Ph.D. ${ }^{1}$ and Stephen Schilling, Ph.D. ${ }^{2}$ \\ ${ }^{1}$ Professor of Anesthesiology, Medicine, Psychiatry and Psychology, Associate Director, Chronic \\ Pain and Fatigue Research Center, The University of Michigan \\ ${ }^{2}$ Senior Psychometrician, English Language Institute Testing Division, The University of Michigan
}

\begin{abstract}
Fibromyalgia (FM) has historically been considered a chronic pain condition. Recent clinical studies however reveal that while pain may be the cardinal symptom of FM, there are many other symptoms and consequences of having FM that impact the lives of individuals with this condition. As such, an area of intense clinical research has focused upon improving approaches to assessment for FM. This article provides an overview of how the art of assessing FM has evolved over time, the value of patients' perspectives in assessment, current methods of assessment, and emerging advancements representing the future of assessment for FM.
\end{abstract}

Fibromyalgia (FM) is a manifestation of chronic widespread pain (CWP) and tenderness with a prevalence of $2 \%$ in the general population (Wolfe et al., 1995). Clinically, individuals with FM present with a variety of physical symptoms that include widespread pain and tenderness but also fatigue, sleep disturbance, decrements in physical functioning, mood disturbances, and problems with cognition (e.g., memory problems, concentration difficulties, diminished mental clarity (Bennett et al., 2007; Mease et al., 2008). FM occurs more frequently in females (Wolfe et al., 1995) and is associated with overall diminished quality of life (Forseth \& Gran, 2002), diminished functional status (Hoffman \& Dukes, 2008), and higher than expected healthcare utilization (Berger et al., 2007).

Emerging insights into the pathophysiology of FM suggest that it is a disorder of central sensory processing often comprising a genetic predisposition and exposure to stressors of a physical or psychological nature (Ablin et al., 2008; Staud \& Rodriguez, 2006; Dadabhoy \& Clauw, 2005). In part, the augmented experience of pain in individuals with FM is thought to be associated with either (a) excessive spinal facilitation of afferent nociceptive signaling to higher cortical pain processing regions or (b) deficiencies in descending cortical mechanisms responsible for dampening nociception (Yoshimura \& Furue, 2006; Staud \& Spaeth, 2008). As such, recent clinical trials have explored the use of pharmacological compounds targeting one or both of these mechanisms with measured success (Mease et al., 2009b; Arnold et al., 2008b; Mease et al., 2009a; Clauw et al., 2008). Pharmacological compounds however are neither curative nor address all aspects of this condition and as such, non-pharmacological approaches continue to play an important role in the comprehensive management of FM (Goldenberg et al., 2004).

(C) 2009 Elsevier Inc. All rights reserved.

Address all correspondence to: David A. Williams, Ph.D., Chronic Pain \& Fatigue Research Center, University of Michigan, 24 Frank Lloyd Wright Drive, Lobby M, Ann Arbor, MI 48106, Phone: 734 998-6961, FAX: 734 998-6900, email: E-mail: daveawms@umich.edu.

Publisher's Disclaimer: This is a PDF file of an unedited manuscript that has been accepted for publication. As a service to our customers we are providing this early version of the manuscript. The manuscript will undergo copyediting, typesetting, and review of the resulting proof before it is published in its final citable form. Please note that during the production process errors may be discovered which could affect the content, and all legal disclaimers that apply to the journal pertain. 
Despite attempts to identify sensitive and specific biomarkers for FM, patients' self-report remains the best clinical approach to understanding the experience of FM for most individuals. This manuscript provides a brief review of several topics pertinent to understanding current practices in the assessment of FM. These include the following: (a) viewing FM as a member of a larger chronic illness continuum, (b) understanding the value of patient reported outcomes (PROs), (c) identifying the relevant domains of assessment for FM and how to assess them, and (d) reviewing emerging trends in the future of multidimensional assessment.

\section{FM as a Member of a Larger Chronic Illness Continuum}

What is now termed "Fibromyalgia" was earlier considered to be fibrositis. The change in nomenclature occurred in the mid-1970s (Smythe \& Moldofsky, 1977) to reflect the lack of evidence for any inflammation in the connective tissues of individuals presenting with this condition. Researchers needed a means of quantifying the pain experience in these patients and as such, chose to quantify tender points (regions of extreme tenderness). With this choice, FM became a condition of both pain and tenderness - two constructs which may or may not be synonymous with one another (Wolfe et al., 1990).

Many researchers within the field of chronic pain believe that chronic pain itself is a "disease". The underlying mechanisms of this disease may in fact be similar across many pain conditions previously considered "idiopathic" or "functional" pain syndromes and operate similarly regardless of whether the pain is present throughout the body (e.g. in FM) or localized to specific regions (e.g. low back, the bowel, or the bladder). Although treated as separate conditions, disorders such as FM, irritable bowel syndrome (IBS), temporomandibular disorder (TMD), and vulvodynia, may in fact share more commonalities in their etiologies than differences. Such similarities however get masked due to these conditions being represented in separate clinics, and evaluated by separate medical sub-specialties and separate teams of researchers. When co-morbidities of these conditions are assessed, having more than one of these conditions at a given time is quite common (Clauw \& Chrousos, 1997). Appendix 1 offers a symptom checklist and diagnostic module research tool for identifying co-morbidities in this spectrum of illness. The tool has two parts: (a) a self-reported symptom checklist that serves as a screening tool for conditions in this spectrum of illness, and (b) the specific diagnostic criteria for the various co-morbidities that can be assessed via interview between patients and clinical staff. Greater endorsement of symptoms on this checklist has been associated with more profound overall severity and impact of illness within this spectrum helping to underscore the inter-relatedness of symptoms within these conditions (Geisser et al., 2008).

\section{The Value of Patient Reported Outcomes}

The adoption of the tender point count was an attempt to objectify the pain report of patients with FM. The biomedical community has historically relied upon and valued objective measures of physiological activity or structure to assess the health of patients (e.g. lab values, radiographic images, biomarkers etc.). While these measures can be remarkably accurate for measuring specific physiological constructs (e.g. bone healing, blood flow), these markers cannot capture the more subjective perceptions of patients' health, well-being, and healthrelated quality of life (HRQoL) thought to drive much of the variance in outcomes and health care utilization in chronic illnesses (Jiang \& Hesser, 2008; Dominick et al., 2004). For example, if a patient with intermittent but chronic headaches attended an office visit where she was evaluated as being physically normal, it would be incorrect to infer this patient possessed a good HRQoL.

For many medical conditions, objective physical measures and/or measures of functional capacity correlate only modestly with patient-reported measures of symptoms or HRQoL (e.g. rarely above 0.40 and more typically below 0.20 ) (Hahn et al., 2007). In a study of patients 
with FM, functional status was assessed both by actigraphy and by self-report. The self-report data revealed far worse functional status than did the actigraphy monitoring (Kop et al., 2005). Similar differences between objective methods and self-report have been identified in the measurement of cognitive status (e.g. self-report differs markedly from the more objective neuropsychological assessment), (Snitz et al., 2008), measures of sleep quality differ markedly depending upon whether measured by self-report or by polysomnography (e.g. correlations between 0.06-0.32) (Unruh et al., 2008), and self-reported clinical pain is only modestly associated with more objective evoked pain ratings of tenderness derived from heat, dolorimeter, and pressure (Geisser et al., 2007).

It is tempting to conclude that the "objective clinical" measures represent "truth" while the "subjective patient-reported" measures represent inaccuracies (e.g. noise, bias, psychological factors, error) but this would be a mistake. Both are linked to clinically-relevant outcomes; yet the low to modest relationship between these two types of measures suggests that they are capturing unique information related to health and both are necessary to understand the clinical picture of a given patient (Hahn et al., 2007).

\section{Can the Disorder be Measured Separately from the Quality of Life?}

In chronic illnesses, by definition, there is no cure available; thus, interventions for chronic illnesses at best serve to manage the condition while it persists within the individual. Chronic illness management interventions seek to arrest progression, palliate symptoms, elicit patients' involvement in self-care, reduce symptoms, improve function, and help to restore the dignity of the individual living with the illness. For chronic illnesses, there can not be a single biomarker that captures all of these matters or that adequately measures the totality of the illness process and its impact on the individual. To state that measuring the cardinal symptom of the illness is paramount and that HRQoL is secondary, misses the fact that with chronicity, matters of health-related quality of life become inseparably fused into the chronic illness itself and must be meaningfully assessed and included in a comprehensive management plan for the individual.

In general terms, HRQOL is thought to encompass a number of primary domains (i.e. physical functioning, psychological functioning, social functioning, overall life satisfaction/well-being, perceptions of health status) and secondary domains (i.e. neuropsychological functioning, personal productivity, intimacy and sexual functioning, sleep quality, pain, symptoms of illness, spirituality) (Naughton \& Shumaker, 2003). While it can be seen how the treatment of a finger laceration within the biomedical model might not need to fully consider HRQOL domains, it is nearly impossible to consider the experience of a condition like FM in the absence of most of these domains.

\section{Identifying Relevant Domains of Assessment for FM}

The Outcomes Measures in Rheumatology (OMERACT) organization has helped to resolve problems in outcomes measurement by establishing core data sets that should be collected and reported in clinical trials involving rheumatological conditions (Tugwell et al., 2007). One task force within OMERACT has focused upon domains of relevance to FM. With initial work dating back to 2004, two Delphi studies have been conducted in an attempt to establish consensus regarding the clinical domains impacted by FM. These two studies, one conducted within patients with FM (Mease et al., 2008; Arnold et al., 2008a) and a second conducted with clinicians (Mease et al., 2005; Mease et al., 2008) revealed remarkable consensus regarding the need to assess multiple domains in FM including pain, fatigue, functional status, sleep, mood, tenderness/stiffness, and problems with concentration/memory (i.e. dyscognition). 
The Initiative on Methods, Measurement, and Pain Assessment in Clinical Trials (IMMPACT) is a second organization focused upon identifying the domains that should be assessed in research involving chronic pain more generally. This group identifies 4 core areas for assessment: (1) pain intensity, (2) physical functioning, (3) emotional functioning, and (4) overall improvement/well-being (Dworkin et al., 2008). Although independent organizations, the remarkable agreement between these two groups regarding thorough assessment of individuals having painful conditions provides confidence that assessment of pain intensity alone is largely insufficient for chronic pain conditions like FM.

While OMERACT and IMMPACT offer guidance as to the domains of relevance for chronic pain conditions, the actual assessment of those domains has been done with a variety of assessment instruments (Mease, 2005; Arnold et al., 2000; Offenbacher et al., 2007). The next section reviews some of the more commonly used assessment instruments associated with the domains of relevance for FM.

Pain in FM is most commonly assessed using either the McGill Pain Questionnaire (MPQ; (Melzack, 1975; Melzack, 1987)), or the Brief Pain Inventory (BPI; (Keller et al., 2004)). These measures have been found to be relatively good generic instruments for the assessment of pain and its various parameters (e.g. quality, quantity, spatial location, temporal occurrence, affect, and behavioral impact). In as much as the pain associated with FM is similar to other forms of chronic pain, these instruments are likely to perform well (Dworkin et al., 2005; Jensen et al., 1998; Jensen \& McFarland, 1993).

Eighty-one percent of patients with FM also report having fatigue (Wolfe et al., 1990). Multiple measures have been used in the assessment of fatigue. Some measures are unidimensional visual analogue scales while others attempt to assess multiple dimensions of fatigue involving physical fatigue, mental fatigue, motivation, etc. Examples of multidimensional fatigue instruments include The Multidimensional Assessment of Fatigue (MAF; (Belza et al., 1993)), the Fatigue subscale of the Profile of Mood States (POMS; (McNair et al., 1971)), the Profile of Fatigue-Related Symptoms (PFRS; (Ray et al., 1992)), the Fatigue Severity Scale (FSS; (Krupp et al., 1989)), and the Multidimensional Fatigue Inventory (MFI;(Smets et al., 1995)). Many of these instruments were originally developed in the realm of cancer research and then applied to FM after being used in at least one study involving a rheumatologic population.

Sleep disturbances affect $75 \%$ of patients with FM (Wolfe et al., 1990). Like fatigue measures, there are both unidimensional VAS scales (e.g. sleep quality, difficulty falling asleep, difficulty staying asleep, or impact of sleep) and multidimensional scales. Examples of multidimensional scales include the MOS sleep scale (Hays \& Stewart, 1992), the Pittsburgh Sleep Quality Index (PSQI; (Buysse et al., 1989)), and The Sleep Assessment Questionnaire (SAQ; (Cesta et al., 1999)). Also like the fatigue measures, many of the measures of sleep were borrowed from other clinical populations with little validation occurring specifically in FM.

A patient need not be psychiatrically ill in order to have matters of affect influence pain and well-being. Many measures of affect have been used in the assessment of FM and a sampling is listed below. Depressive symptoms are often assessed by the Beck Depression Inventory (BDI-II) (Beck et al., 1996)) a widely used instrument in mental health research. The Center for Epidemiological Studies-Depression Scale (CES-D; (Radloff, 1977)), and the patient health Questionnaire (PHQ; (Kroenke et al., 2001)), are instruments that are often used to detect depressive symptoms in the general population. Measures of anxiety include the Beck Anxiety Inventory (BAI; (Beck \& Steer, 1990)), and the State Trait Anxiety Inventory (STAI;

(Spielberger et al., 1979)). The Hospital Anxiety and Depression Scale (HADS; (Zigmond \& Snaith, 1983)) is a single instrument that captures both depressive and anxiety symptoms. More 
general measures of multiple moods include the Profile of Mood States (POMS; (McNair et al., 1971)), and the Positive and Negative Affect Scale (PANAS; (Watson et al., 1988)).

Patients with FM often complain of "fibro-fog" or "dyscognition". No clear definition exists for fibro-fog; however it tends to refer to a composite experience involving slowing of information processing, difficulties in multi-tasking particularly under distracting conditions, failures of memory, poor concentration and clarity of thought and perceived deficits in executive function. Despite its importance, to date, there is no simple measure of dyscognition available for patients with FM (Silverman \& Martin, 2005). One measure that does tap a number of domains of perceived cognitive difficulties is the Multiple Ability Self-Report Questionnaire (MASQ;(Seidenberg et al., 1994)). This brief questionnaire is comprised of 5 cognitive domains: language ability, visuo-perceptual ability, verbal memory, visual memory, and attention/concentration. Where as the MASQ is a self-report measure of perceived cognitive difficulty, other more objective neuropsychological batteries of cognitive performance may be able to offer additional insight into the nature of "fibro-fog" within individuals.

In the context of functional status, patients with FM often complain of stiffness. To date, there are only a few measures of stiffness. These include the WOMAC (Bellamy et al., 1988), an instrument addressing stiffness in the context of arthritis, and a single item VAS in the Fibromyalgia Impact Questionnaire, (FIQ; (Burckhardt et al., 1991)), one of the few diseasespecific measures of FM.

Other measures of functional status include the Stanford Health Assessment Questionnaire (HAQ; (Fries et al., 1980)) which has been adapted into a FM-specific functional assessment tool (F-HAQ; (Wolfe et al., 2000)) and the SF-36 (Ware et al., 2000) perhaps the most commonly used measure of functional status and HRQoL in clinical outcomes research.

As is evident from the text above, the assessment of multiple domains can require a great deal of time and effort on the part of the patient. For both clinical and research purposes, it is preferable to use assessment instruments possessing strong support of validity in each domain for specific chronic illnesses. In the case of FM, early work in this area required that instruments be borrowed from other diseases given that the research criteria for FM was established only as recently as 1990 and consensus as to domains of relevance is still emerging. Clearly, sufficient time has not passed to develop new disease-specific measures for each of the relevant domains in FM or to conduct studies supporting the valid use of existing (i.e. legacy) instruments specifically in the context of FM.

\section{Moving Beyond Legacy Measures}

Even when disease-specific measures exist, we can not be certain that sufficient methodological rigor has accompanied their development. The Institutes, Agencies, and Centers that comprise the US Department of Health and Human Services (DHHS) has recognized that heath outcomes research in general is hampered by three broad problems: (a) a reliance upon legacy instruments developed within disease-specific silos having variable psychometric properties and/or relevance to HRQOL, (b) an inability to compare outcomes across disease states due to different measures and scaling being used, and (c) inefficiencies in assessing multiple domains of clinical relevance. In order to address these problems, NIH launched a Roadmap initiative known as PROMIS (Patient-Reported Outcomes Measurement Information System), a large scale assessment infrastructure to develop brief, yet valid assessments of multiple domains of quality of life (Reeve et al., 2007a).

In the development of PROMIS, domains of quality of life were identified that reflected many of the domains described earlier; initially, these included (1) physical functioning, (2) fatigue, (3) pain, (4) emotional distress, (5) social role participation, and several global items (Cella et 
al., 2007). Rather than relying upon classical approaches of test construction where reliability and validity depends heavily upon completion of each item within the test, PROMIS borrowed methods long used successfully in educational testing - item response theory (IRT) and computer adaptive testing (CAT). For these methods, large item banks representing aspects of a given domain (e.g. pain, fatigue) are used. Each item within the item bank is analyzed and calibrated along the domain of interest using factor analytic methods and IRT. The possession of the performance characteristics of each item permits the development and use of CAT. Whereas in classically constructed tests all items on the test would need to be administered to an individual in order to obtain a valid score, CAT only delivers a few items from the overall item bank representing the domain of interest. It does this by first delivering a seed item and then depending upon the response to the seed, returns to the item bank to select the next item that provides the most relevant additional information about the domain. For example, if assessing physical functioning, a patient might be asked about getting out of bed, walking, climbing stairs, and running. Under a classically developed test, all items would need to be administered even if the patient indicated that he/she could not get out of bed. Under CAT, only items that add precision to the measurement of the domain for that individual are needed. While each individual taking the CAT would receive different items, all items within the bank reflect aspects of a common domain.

In the development of PROMIS, an item library was created by assembling the many existing legacy questionnaires purporting to measure each domain. The entire item library contained over 10,000 entries and as might be expected there were many redundancies. A qualitative process known as "binning and winnowing" was used to refine the library as were patient focus groups, expert consultation, the re-writing of items, cognitive interviewing and standardization of the item stems and response sets (Cella et al., 2007) .

Each item bank was field tested in thousands of individuals in order to conduct the psychometric evaluation of the banks. Quantitative evaluation included traditional descriptive statistics (i.e. item analysis and scale analysis), evaluation of the assumptions of IRT (i.e. unidimensionality, local independence, and monotonacity), fitting of the IRT model to the data (i.e. estimation of IRT model parameters, examination of model fit, evaluation of item and scale properties), evaluation of differential item functioning (DIF) among demographic and clinical groups, and item calibration for item banking (i.e. standardized theta metric for US population and clinical groups, and identifying discrimination and threshold parameters for use in CAT algorithms) (Reeve et al., 2007b). In addition to the use of CAT, static short forms containing highly relevant items for specific clinical populations have also been developed and evaluated.

PROMIS can be used clinically or for research purposes for the efficient and generic measurement of patient reported outcomes (PROs) across a wide range of chronic diseases and dimensions (Fries et al., 2005). The benefit of this system is the ability to assess multiple domains using fewer items (i.e. less patient burden) with greater precision (i.e. increased power for clinical trials with fewer subjects). While PROMIS was established for the general assessment of chronic illnesses; greater precision can be attained when the item banks are further calibrated to be used with specific illnesses. Currently a disease-specific calibration of PROMIS item banks for use in FM is underway as a cooperative agreement between the University of Michigan and NIAMS/NIH. In this study, the existing item banks within PROMIS are being calibrated in field tests requiring thousands of individuals with FM so that CATs can be developed with algorithms specific to FM.

\section{Future Assessment in FM}

With assessment tools like those of PROMIS, both researchers and clinicians will be able to evaluate the multiple domains of relevance to individuals suffering with FM and related conditions with greater precision and efficiency. Still lacking for PROMIS and for the field of 
FM research generally however are consensual demarcations indicative of clinically meaningful change in each of the domains or composites of domains. Work in this area is being advanced by investigators at the University of Cincinnati (i.e., Lesley Arnold) in conjunction with NIAMS/NIH and by other collaborators within OMERACT specifically for FM and by IMMPACT for chronic pain more generally (Dworkin et al., 2008). As interventions for FM become more specialized by targeting various aspects of FM, (e.g. pain, function, sleep, fatigue, etc), it is likely that more and more specialized assessment tools will be needed. The development of high quality assessment instruments for FM is recognized by academia and by industry as a high priority research agenda item. As FM appears to represent one of several conditions within a broader sphere of central pain disorders, it is likely that advances in the assessment of FM will translate into benefits for other chronic pain conditions as well.

\section{Acknowledgments}

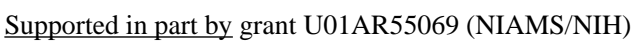

\section{Reference List}

Ablin J, Neumann L, Buskila D. Pathogenesis of fibromyalgia - a review. Joint Bone Spine 2008;75:273279. [PubMed: 18375167]

Arnold LM, Crofford LJ, Mease PJ, Burgess SM, Palmer SC, Abetz L, et al. Patient perspectives on the impact of fibromyalgia. Patient.Educ.Couns 2008a;73:114-120. [PubMed: 18640807]

Arnold LM, Keck PEJ, Welge JA. Antidepressant treatment of fibromyalgia. A meta-analysis and review. Psychosomatics 2000;41:104-113. [PubMed: 10749947]

Arnold LM, Russell IJ, Diri EW, Duan WR, Young JP Jr, Sharma U, et al. A 14-week, randomized, double-blinded, placebo-controlled monotherapy trial of pregabalin in patients with fibromyalgia. J.Pain 2008b;9:792-805. [PubMed: 18524684]

Beck, AT.; Steer, RA. Beck Anxiety Inventory: Manual. Vol. 2 ed.. San Antonio: The Psychological Corporation Harcourt Brace Jovanovich, Inc; 1990.

Beck, AT.; Steer, RA.; Brown, GK. Manual for the Beck Depression Inventory-II. San Antonio, TX: Psychological Corporation; 1996.

Bellamy N, Buchanan WW, Goldsmith CH, Campbell J, Stitt LW. Validation study of WOMAC: a health status instrument for measuring clinically important patient relevant outcomes to antirheumatic drug therapy in patients with osteoarthritis of the hip or knee. Journal of Rheumatology 1988;15:18331840. [PubMed: 3068365]

Belza BL, Henke CJ, Yelin EH, Epstein WV, Gilliss CL. Correlates of fatigue in older adults with rheumatoid arthritis. Nurs.Res 1993;42:93-99. [PubMed: 8455994]

Bennett RM, Jones J, Turk DC, Russell IJ, Matallana L. An internet survey of 2,596 people with fibromyalgia. BMC.Musculoskelet.Disord 2007;8:27-38. [PubMed: 17349056]

Berger A, Dukes E, Martin S, Edelsberg J, Oster G. Characteristics and healthcare costs of patients with fibromyalgia syndrome. Int.J Clin.Pract 2007;61:1498-1508. [PubMed: 17655684]

Burckhardt CS, Clark SR, Bennett RM. The fibromyalgia impact questionnaire: Development and validation. Journal of Rheumatology 1991;18:728-733. [PubMed: 1865419]

Buysse DJ, Reynolds CF III, Monk TH, Berman SR, Kupfer DJ. The Pittsburgh Sleep Quality Index: a new instrument for psychiatric practice and research. Psychiatry Res 1989;28:193-213. [PubMed: 2748771]

Cella D, Yount S, Rothrock N, Gershon R, Cook K, Reeve B, et al. The Patient-Reported Outcomes Measurement Information System (PROMIS): progress of an NIH Roadmap cooperative group during its first two years. Med Care 2007;45:S3-S11. [PubMed: 17443116]

Cesta A, Moldofsky H, Sammut C. The sensitivity and specificity of the Sleep Assessment Questionnaire (SAQ) as a measure of nonrestorative sleep. Sleep 1999;22:14.

Clauw DJ, Chrousos GP. Chronic pain and fatigue syndromes: Overlapping clinical and neuroendocrine features and potential pathogenic mechanisms. Neuroimmunomodulation 1997;4:134-153. [PubMed: 9500148] 
Clauw DJ, Mease P, Palmer RH, Gendreau RM, Wang Y. Milnacipran for the treatment of fibromyalgia in adults: a 15-week, multicenter, randomized, double-blind, placebo-controlled, multiple-dose clinical trial. Clin.Ther 2008;30:1988-2004. [PubMed: 19108787]

Dadabhoy D, Clauw DJ. Fibromyalgia: progress in diagnosis and treatment. Curr.Pain Headache Rep 2005;9:399-404. [PubMed: 16282040]

Dominick KL, Ahern FM, Gold CH, Heller DA. Health-related quality of life and health service use among older adults with osteoarthritis. Arthritis Rheum 2004;51:326-331. [PubMed: 15188315]

Dworkin RH, Turk DC, Farrar JT, Haythornthwaite JA, Jensen MP, Katz NP, et al. Core outcome measures for chronic pain clinical trials: IMMPACT recommendations. Pain 2005;113:9-19. [PubMed: 15621359]

Dworkin RH, Turk DC, Wyrwich KW, Beaton D, Cleeland CS, Farrar JT, et al. Interpreting the clinical importance of treatment outcomes in chronic pain clinical trials: IMMPACT recommendations. J Pain 2008;9:105-121. [PubMed: 18055266]

Forseth KO, Gran JT. Management of fibromyalgia: what are the best treatment choices? Drugs 2002;62:577-592. [PubMed: 11893227]

Fries JF, Bruce B, Cella D. The promise of PROMIS: using item response theory to improve assessment of patient-reported outcomes. Clin.Exp.Rheumatol 2005;23:S53-S57. [PubMed: 16273785]

Fries JF, Spitz P, Kraines RG, Holman HR. Measurement of patient outcome in arthritis. Arthritis \& Rheumatism 1980;23:137-145. [PubMed: 7362664]

Geisser ME, Gracely RH, Giesecke T, Petzke FW, Williams DA, Clauw DJ. The association between experimental and clinical pain measures among persons with fibromyalgia and chronic fatigue syndrome. Eur.J Pain 2007;11:202-207. [PubMed: 16546424]

Geisser ME, Strader DC, Petzke F, Gracely RH, Clauw DJ, Williams DA. Comorbid somatic symptoms and functional status in patients with fibromyalgia and chronic fatigue syndrome: sensory amplification as a common mechanism. Psychosomatics 2008;49:235-242. [PubMed: 18448779]

Goldenberg DL, Burckhardt C, Crofford L. Management of fibromyalgia syndrome. JAMA 2004;292:2388-2395. [PubMed: 15547167]

Hahn EA, Cella D, Chassany O, Fairclough DL, Wong GY, Hays RD. Precision of health-related qualityof-life data compared with other clinical measures. Mayo Clin.Proc 2007;82:1244-1254. [PubMed: 17908530]

Hays, RD.; Stewart, A. Sleep Measures. In: Stewart, AL.; Ware, JE., editors. Measuring functioning and well-being : the medical outcomes study approach. Durham: Duke University Press; 1992. p. 235-259.

Hoffman DL, Dukes EM. The health status burden of people with fibromyalgia: a review of studies that assessed health status with the SF-36 or the SF-12. Int.J Clin.Pract 2008;62:115-126. [PubMed: 18039330]

Jensen MP, McFarland CA. Increasing the reliability and validity of pain intensity measurement in chronic pain patients. Pain 1993;55:195-203. [PubMed: 8309709]

Jensen MP, Miller L, Fisher LD. Assessment of pain during medical procedures: A comparison of three scales. Clinical Journal of Pain 1998;14:343-349. [PubMed: 9874014]

Jiang Y, Hesser JE. Patterns of health-related quality of life and patterns associated with health risks among Rhode Island adults. Health Qual.Life Outcomes 2008;6:49. [PubMed: 18620582]

Keller S, Bann CM, Dodd SL, Schein J, Mendoza TR, Cleeland CS. Validity of the brief pain inventory for use in documenting the outcomes of patients with noncancer pain. Clin J Pain 2004;20:309-318. [PubMed: 15322437]

Kop WJ, Lyden A, Berlin AA, Ambrose K, Olsen C, Gracely RH, et al. Ambulatory monitoring of physical activity and symptoms in fibromyalgia and chronic fatigue syndrome. Arthritis Rheum 2005;52:296-303. [PubMed: 15641057]

Kroenke K, Spitzer RL, Williams JB. The PHQ-9: validity of a brief depression severity measure. J.Gen.Intern.Med 2001;16:606-613. [PubMed: 11556941]

Krupp LB, LaRocca NG, Muir-Nash J, Steinberg AD. The fatigue severity scale. Application to patients with multiple sclerosis and systemic lupus erythematosus. Arch.Neurol 1989;46:1121-1123.

McNair, D.; Lorr, M.; Droppleman, L. Manual for the profile of mood states. San Diego: Educational Testing Service; 1971. 
Mease P. Fibromyalgia syndrome: review of clinical presentation, pathogenesis, outcome measures, and treatment. J Rheumatol.Suppl 2005;75:6-21. [PubMed: 16078356]

Mease PJ, Arnold LM, Crofford LJ, Williams DA, Russell IJ, Humphrey L, et al. Identifying the clinical domains of fibromyalgia: contributions from clinician and patient Delphi exercises. Arthritis Rheum 2008;59:952-960. [PubMed: 18576290]

Mease PJ, Clauw DJ, Arnold LM, Goldenberg DL, Witter J, Williams DA, et al. Fibromyalgia syndrome. J.Rheumatol 2005;32:2270-2277. [PubMed: 16265715]

Mease PJ, Clauw DJ, Gendreau RM, Rao SG, Kranzler J, Chen W, et al. The efficacy and safety of milnacipran for treatment of fibromyalgia. a randomized, double-blind, placebo-controlled trial. $\mathrm{J}$ Rheumatol 2009a;36:398-409. [PubMed: 19132781]

Mease PJ, Russell IJ, Kajdasz DK, Wiltse CG, Detke MJ, Wohlreich MM, et al. Long-Term Safety, Tolerability, and Efficacy of Duloxetine in the Treatment of Fibromyalgia. Semin.Arthritis Rheum. $2009 \mathrm{~b}$

Melzack R. The McGill Pain Questionnaire: Major properties and scoring methods. Pain 1975;1:277299. [PubMed: 1235985]

Melzack R. The short-form McGill Pain Questionnaire. Pain 1987;30:191-197. [PubMed: 3670870]

Naughton MJ, Shumaker SA. The case for domains of function in quality of life assessment. Qual.Life Res 2003;12:73-80. [PubMed: 12803313]

Offenbacher M, Cieza A, Brockow T, Amann E, Kollerits B, Stucki G. Are the contents of treatment outcomes in fibromyalgia trials represented in the International Classification Of Functioning, Disability, and Health? Clin.J Pain 2007;23:691-701. [PubMed: 17885348]

Radloff LS. The CES-D Scale: A self-report depression scale for research in the general population. Applied Psychological Measurement 1977;1:385-401.

Ray C, Weir W, Phillips S, Cullen S. Development of a measure of symptoms in chronic fatigue syndrome: The profile of fatigue related symptoms (PFRS). Psychology and Health 1992;7:27-43.

Reeve BB, Burke LB, Chiang YP, Clauser SB, Colpe LJ, Elias JW, et al. Enhancing measurement in health outcomes research supported by Agencies within the US Department of Health and Human Services. Qual.Life Res 2007a;16:175-186. [PubMed: 17530449]

Reeve BB, Hays RD, Bjorner JB, Cook KF, Crane PK, Teresi JA, et al. Psychometric evaluation and calibration of health-related quality of life item banks: plans for the Patient-Reported Outcomes Measurement Information System (PROMIS). Med Care 2007b;45:S22-S31. [PubMed: 17443115]

Seidenberg M, Haltiner A, Taylor MA, Hermann BB, Wyler A. Development and validation of a Multiple Ability Self-Report Questionnaire. Journal of Clinical \& Experimental Neuropsychology 1994;16:93-104. [PubMed: 8150893]

Silverman, SL.; Martin, SA. Assessment Tools and Outcome Measures Used in the Investigation of Fibromyalgia. In: Wallace, DJ.; Clauw, DJ., editors. Fibromyalgia \& Other Central Pain Syndromes. Philadelphia, PA: Lippincott Williams \& Wilkins; 2005. p. 309-319.

Smets EM, Garssen B, Bonke B, De Haes JC. The Multidimensional Fatigue Inventory (MFI) psychometric qualities of an instrument to assess fatigue. Journal of Psychosomatic Research 1995;39:315-325. [PubMed: 7636775]

Smythe HA, Moldofsky H. Two contributions to understanding of the "fibrositis" syndrome. Bulletin on the Rheumatic Diseases 1977;28:928-931. [PubMed: 199304]

Snitz BE, Morrow LA, Rodriguez EG, Huber KA, Saxton JA. Subjective memory complaints and concurrent memory performance in older patients of primary care providers. J Int.Neuropsychol.Soc 2008;14:1004-1013. [PubMed: 18954480]

Spielberger, CD.; Gorsuch, RL.; Lushene, R. Manual for the State-Trait Anxiety Inventory: (STAI) "(Self-Evaluation Questionnaire)". Palo Alto: Consulting Psychologists Press; 1979.

Staud R, Rodriguez ME. Mechanisms of disease: pain in fibromyalgia syndrome. Nat.Clin.Pract.Rheumatol 2006;2:90-98. [PubMed: 16932662]

Staud R, Spaeth M. Psychophysical and neurochemical abnormalities of pain processing in fibromyalgia. CNS.Spectr 2008;13:12-17. [PubMed: 18323768]

Tugwell P, Boers M, Brooks P, Simon L, Strand V, Idzerda L. OMERACT: An international initiative to improve outcome measurement in rheumatology. Trials 2007;8:38. [PubMed: 18039364] 
Unruh ML, Redline S, An MW, Buysse DJ, Nieto FJ, Yeh JL, et al. Subjective and objective sleep quality and aging in the sleep heart health study. J Am.Geriatr.Soc 2008;56:1218-1227. [PubMed: 18482295]

Ware, JE.; Snow, K.; Kosinski, M. SF-36® Health Survey: Manual and Interpretation Guide. Lincoln, RI: QualityMetric, Inc; 2000.

Watson D, Clark LA, Tellegen A. Development and validation of brief measures of positive and negative affect: the PANAS scales. J Pers.Soc.Psychol 1988;54:1063-1070. [PubMed: 3397865]

Wolfe F, Hawley DJ, Goldenberg DL, Russell IJ, Buskila D, Neumann L. The assessment of functional impairment in fibromyalgia (FM): Rasch analyses of 5 functional scales and the development of the FM Health Assessment Questionnaire. J Rheumatol 2000;27:1989-1999. [PubMed: 10955343]

Wolfe F, Ross K, Anderson J, Russell IJ, Hebert L. The prevalence and characteristics of fibromyalgia in the general population. Arthritis Rheum 1995;38:19-28. [PubMed: 7818567]

Wolfe F, Smythe HA, Yunus MB, Bennett RM, Bombardier C, Goldenberg DL, et al. The American College of Rheumatology 1990 Criteria for the Classification of Fibromyalgia. Report of the Multicenter Criteria Committee. Arthritis \& Rheumatism 1990;33:160-172.

Yoshimura M, Furue H. Mechanisms for the anti-nociceptive actions of the descending noradrenergic and serotonergic systems in the spinal cord. J Pharmacol.Sci 2006;101:107-117. [PubMed: $16766858]$

Zigmond AS, Snaith RP. The hospital anxiety and depression scale. Acta Psychiatr.Scand 1983;67:361370. [PubMed: 6880820]

\section{Appendix}

\section{Appendix 1}

The Complex Medical Symptoms Inventory (CMSI) is a diagnostic tool to assist in identifying the presence of conditions that commonly accompany FM. The tool consists of two parts: (a) a symptom checklist that serves as a screener and (b) the published diagnostic criteria for several of the more common conditions within this spectrum of illnesses. The latter is to be administered by staff interview.

[see CMSI document sent separately] 